Article

\title{
The Effect of Combining Natural Terpenes and Antituberculous Agents against Reference and Clinical Mycobacterium tuberculosis Strains
}

\author{
Elwira Sieniawska ${ }^{1, *}$, Rafal Sawicki ${ }^{2}$, Marta Swatko-Ossor ${ }^{2}$, Agnieszka Napiorkowska $^{3}$ (D), \\ Agata Przekora ${ }^{2}$, Grazyna Ginalska ${ }^{2}$ and Ewa Augustynowicz-Kopec ${ }^{3}$ \\ 1 Department of Pharmacognosy with Medicinal Plant Unit, Medical University of Lublin, \\ 20-093 Lublin, Poland \\ 2 Department of Biochemistry and Biotechnology, Medical University of Lublin, 20-093 Lublin, Poland; \\ rafal.sawicki@umlub.pl (R.S.); martaswatkoossor@umlub.pl (M.S.-O.); agata.przekora@umlub.pl (A.P.); \\ grazynaginalska@umlub.pl (G.G.) \\ 3 Department of Microbiology, National Tuberculosis and Lung Diseases Research Institute, \\ 01-138 Warsaw, Poland; a.napiorkowska@igichp.edu.pl (A.N.); e.kopec@igichp.edu.pl (E.A.-K.) \\ * Correspondence: elwira.sieniawska@pharmacognosy.org; Tel.: +48-81-448-7080
}

Received: 28 November 2017; Accepted: 6 January 2018; Published: 15 January 2018

\begin{abstract}
Background: On account of emergence of multi- and extensively drug-resistant Mycobacterium tuberculosis (Mtb) strains, combinations of drugs with natural compounds were tested to search for antibiotic activity enhancers. In this work we studied terpenes ( $\alpha$-pinene, bisabolol, $\beta$-elemene, $(R)$-limonene, (S)-limonene, myrcene, sabinene), which are the main constituents of essential oil obtained from Mutellina purpurea L., a plant with described antitubercular activity, to investigate their interactions with antibiotics against reference Mtb strains and multidrug-resistant clinical isolates. Methods: The serial dilution method was used to evaluate the minimal inhibitory concentration (MIC) of tested compounds, while the fractional inhibitory concentration index (FICI) was calculated for characterization of interactions. Moreover, $\mathrm{IC}_{50}$ values of tested compounds were determined using monkey kidney epithelial cell line (GMK). Results: The combinations of all studied terpenes with ethambutol or rifampicin resulted in a synergistic interaction. Bisabolol and $(R)$-limonene decreased the MIC for rifampicin at least two-fold for all tested strains, however no synergistic action was observed against virulent strains. The tested terpenes showed slight (bisabolol) or no cytotoxic effect against normal eukaryotic cells in vitro. Conclusions: The obtained enhanced activity (FICI < 0.5) of ethambutol and rifampicin against H37Ra strain under the influence of the studied terpenes may be correlated to the capability of essential oil constituents to modify bacterial resistance mechanisms in general. The observed differences in avirulent and virulent bacteria susceptibility to terpenes tested separately and in combinations with antibiotics can be correlated with the differences in the cell wall structure between H37Ra mutant and all virulent strains.
\end{abstract}

Keywords: FICI; MDR-TB; clinical isolates; natural terpenes; bisabolol; $(R)$-limonene

\section{Introduction}

Tuberculosis is still a global threat [1], but the emergence of multi- and extremely-drug resistant Mycobacterium tuberculosis (Mtb) strains makes the treatment of this disease much more difficult. Since circulating strains are resistant to various combinations of drugs and the development of new drug leads takes a long time, a different approach is to find adjuvants capable of enhancing the efficacy of antibiotics. An enhancement of microbes' susceptibility to antibiotics was observed under the influence of natural products [2], especially, essential oils [3-7]. Essential oils are known 
for their positive antimicrobial action and many possible mechanisms of their activity against a wide range of bacterial strains have been proposed [8-11]. The studies on synergy between essential oils components [12] as well as on the synergy between essential oils and antibiotics against wide range of microorganisms [13] indicates the possible impact of these compounds on restoring the sensitivity of resistant bacteria to antibiotics. Positive, synergistic interactions $(\mathrm{FICI} \leq 0.5)$ were previously described for the antibiotics ciprofloxacin, gentamicin and polymyxin B with Eucalyptus camaldulensis essential oil against multidrug-resistant Acinetobacter baumannii isolates [3], for norfloxacin and Pelargonium graveolens essential oil against Bacillus cereus and Staphylococcus aureus [14], for ticarcillin, imipenem, gentamicin and tobramycin and Origanum compactum essential oil against Pseudomonas putida [15], to name just a few. However, very little is known about the influence of combinations of antibiotics and essential oils constituents against Mtb. Only trans-cinnamic acid with amikacin as well as cis-cinnamic acid with rifampicin were mentioned to have positive action against isolates of multi-drug resistant $M$. tuberculosis [5,6]. For this reason we selected several natural terpenes ( $\alpha$-pinene, bisabolol, $\beta$-elemene, $(R)$-limonene, $(S)$-limonene, myrcene, sabinene), which are the main constituents of the essential oil obtained from Mutellina purpurea L. (syn. Ligusticum mutellina), a plant with described antitubercular activity [16], to investigate their interactions with antibiotics against different mycobacterial strains. A monoterpene $\alpha$-pinene is the most frequently found in Nature [17]. It is a main constituent in essential oils obtained from coniferous trees and shrubs [18,19], however it was also described in many other essential oils like Rosmarinus officinalis, Satureja montana [20,21], Eucalyptus globulus [22], Melaleuca leucadendron, [23], many other herbs and some citrus fruits essential oils. Myoporum crassifolium and Matricaria recutita are the most abundant sources of bisabolol, although it is present in many plants such as lavender or rosemary $[17,24]$. Rhizome of curcuma is used for $\beta$-elemene isolation, however this compound can be obtained also from Michelia figo, Alisma orientale, Solidago decurrens or Nigella damascena essential oils [25]. Limonene is known from citrus essential oils, where it accounts up to $90 \%$, and is present in both enantiomeric forms $((-)-(S)$-limonene and $(+)-(R)$-limonene) in many other essential oils [17]. Myrcene is other compound very widespread in Nature. It was described in most of the common highly fragrant herbs and spices, among which Humulus lupulus, Laurus nobilis, Thymus vulgaris, Cymbopogon schoenanthus or Ocimum basilicum contain high levels of this compound [17]. Sabinene is frequently present in essential oils. It is a major constituent in Juniperus scopulorum essential oil [26], it is also detected is higher amounts in Myristica fragrans [27], Piper nigrum [28] or Daucus carota essential oils [29].

The previous studies showed that $\alpha$-pinene, myrcene, limonene, bisabolol and M. purpurea essential oilalter the mycobacterial cell shape and homogeneity [30], thereby they may enhance the action of antibiotics. Also the positive influence of these terpenes on activity of first line antibiotics against isolated Mtb was observed [31]. Hence, in this work we aimed to investigateif natural terpenes show any synergistic action with antituberculous agents against multi-drug resistant $\mathrm{MTb}$ clinical strains.

\section{Results}

\subsection{Spoligotyping}

The spoligotyping is an analysis of polymorphism in direct repeat region in M. tuberculosis DNA, which is very diverse in different clinical isolates. It can provide a genotypic classification of investigated strains [32]. The spoligotyping of isolated strains enabled us to the assign genotypic lineages according to SITVIT2 Database. Three strain families: ill-defined T family (clades SIT53 and SIT1558), Beijing and Haarlem family (sublineage H1) were identified (Table 1). The clade assignment demonstrated that susceptible strain belonged to T1 53 spoligotyp, while drug resistant strains were classified as T1 1558, H1 47 and Beijing 1 (Table 1). 
Table 1. Characterization of investigates strains.

\begin{tabular}{ccc}
\hline Strain & Resistance Pattern & Spoligotyp \\
\hline H37RaATTC 25177 & susceptible & H37Ra \\
H37RV ATTC 25618 & susceptible & H37Rv \\
192 & susceptible & T1 53 \\
12331 & IRE & H1 47 \\
$253 / 16$ & IRE & T1 1558 \\
$85 / 13$ & SIRE & Beijing 1 \\
126 & INH & T1 1558
\end{tabular}

IRE—isoniazid, rifampicin and ethambutol resistant; RMP—rifampicin; SIRE—resistant to streptomycin, INH, RMP and EMB; INH—isoniazid.

\subsection{Reference Avirulent Strain $\mathrm{H} 37 \mathrm{Ra}$}

The susceptibility testing for compounds investigated separately revealed that growth of H37Ra strain was inhibited by the lowest concentrations of terpenes compared to other strains. The most effective antimycobacterial activity was shown by $\beta$-elemene and the limonenes $(32 \mu \mathrm{g} / \mathrm{mL}$ ) (Table 2$)$. The evaluation of tuberculostatic activity of antibiotics in the presence of subinhibitory concentrations of terpenes showed that all tested compounds enhanced the activity of ethambutol and rifampicin against H37Ra strain. Several terpenes potentiated also the action of isoniazid (Table 3). When terpenes were tested in the presence of sub-inhibitory concentrations of antibiotics, the activity of terpenes was potentiated and MIC values obtained for terpenes were decreased several dilutions in different combinations (Table 4). The calculation of fractional inhibitory concentration indices enabled to find a synergistic action between antibiotics (ethambutol and rifampicin) and terpenes (Table 5).

Table 2. The minimal inhibitory concentration values (MIC) obtained for compounds tested separately.

\begin{tabular}{cccccccc}
\hline & \multicolumn{7}{c}{ MIC $\boldsymbol{\mu g} / \mathbf{m L}$} \\
\hline EMB & 4 & 0.25 & $<0.125$ & 16 & 64 & 16 & 0.25 \\
RMP & 1 & 0.25 & $<0.125$ & 256 & 4 & 128 & 0.25 \\
INH & 0.125 & $<0.125$ & $<0.125$ & 16 & 8 & 16 & 0.5 \\
a-pinene & 128 & 128 & 128 & $>512$ & 256 & 512 & 128 \\
sabinene & 64 & 128 & 128 & $>512$ & 256 & 512 & 128 \\
bisabolol & 64 & 16 & 16 & 256 & 128 & 128 & 32 \\
$\beta$-elemene & 32 & 256 & 256 & 256 & $>512$ & $>512$ & 256 \\
myrcene & 128 & 256 & 256 & 512 & $>512$ & $>512$ & 256 \\
(S)-limonene & 32 & 256 & 256 & 512 & $>512$ & $>512$ & 256 \\
$(R)$-limonene & 32 & 128 & 128 & 128 & 256 & 256 & 128 \\
\hline
\end{tabular}

EMB—ethambutol; RMP—rifampicin; INH—isoniazid.

Table 3. The minimal inhibitory concentration values (MIC) obtained for antibiotics tested in the presence of subinhibitory concentrations of terpenes CLSI.

\begin{tabular}{cccccccc}
\hline & \multicolumn{7}{c}{ MIC $(\boldsymbol{\mu g} / \mathbf{m L})$ for EMB in a Presence of Terpenes } \\
\cline { 2 - 8 } & H37Ra & H37Rv & $\mathbf{1 9 2}$ & $\mathbf{1 2 3 3 1}$ & $\mathbf{2 5 3 / 1 6}$ & $\mathbf{8 5 / 1 3}$ & $\mathbf{1 2 6}$ \\
\hline --pinene & 1 & 0.125 & $<0.125$ & 16 & 32 & 16 & 0.25 \\
sabinene & 0.5 & 0.25 & $<0.125$ & 16 & 64 & 16 & 0.25 \\
bisabolol & 1 & 0.125 & $<0.125$ & 8 & 32 & 16 & 0.125 \\
$\beta$-elemene & 1 & 0.25 & $<0.125$ & 16 & 64 & 16 & 0.25 \\
myrcene & 0.5 & 0.25 & $<0.125$ & 16 & 64 & 16 & 0.25 \\
$(S)$-limonene & 0.5 & 0.25 & $<0.125$ & 16 & 32 & 16 & 0.25 \\
$(R)$-limonene & 1 & 0.125 & $<0.125$ & 8 & 32 & 16 & 0.125 \\
\hline
\end{tabular}


Table 3. Cont.

\begin{tabular}{|c|c|c|c|c|c|c|c|}
\hline & \multicolumn{7}{|c|}{ MIC $(\mu \mathrm{g} / \mathrm{mL})$ for RMP in a Presence of Terpenes } \\
\hline & H37Ra & H37Rv & 192 & 12331 & $253 / 16$ & $85 / 13$ & 126 \\
\hline$\alpha$-pinene & 0.0625 & 0.25 & $<0.125$ & 256 & 4 & 128 & 0.25 \\
\hline sabinene & 0.0625 & 0.25 & $<0.125$ & 256 & 4 & 128 & 0.25 \\
\hline bisabolol & 0.0625 & 0.125 & $<0.125$ & 128 & 2 & 64 & 0.125 \\
\hline$\beta$-elemene & 0.0625 & 0.25 & $<0.125$ & 256 & 4 & 128 & 0.25 \\
\hline myrcene & 0.125 & 0.25 & $<0.125$ & 256 & 4 & 128 & 0.25 \\
\hline (S)-limonene & 0.125 & 0.25 & $<0.125$ & 256 & 4 & 128 & 0.25 \\
\hline \multirow[t]{3}{*}{ (R)-limonene } & 0.125 & 0.125 & $<0.125$ & 128 & 2 & 64 & 0.125 \\
\hline & \multicolumn{7}{|c|}{ MIC $(\mu \mathrm{g} / \mathrm{mL})$ for INH in a Presence of Terpenes } \\
\hline & H37Ra & H37Rv & 192 & 12331 & 253/16 & $85 / 13$ & 126 \\
\hline$\alpha$-pinene & 0.125 & $<0.125$ & $<0.125$ & 16 & 8 & 16 & 0.5 \\
\hline sabinene & 0.0625 & $<0.125$ & $<0.125$ & 16 & 8 & 16 & 0.5 \\
\hline bisabolol & 0.125 & $<0.125$ & $<0.125$ & 8 & 4 & 8 & 0.25 \\
\hline$\beta$-elemene & 0.0625 & $<0.125$ & $<0.125$ & 16 & 8 & 16 & 0.5 \\
\hline myrcene & 0.0625 & $<0.125$ & $<0.125$ & 16 & 8 & 16 & 0.5 \\
\hline (S)-limonene & 0.0625 & $<0.125$ & $<0.125$ & 16 & 8 & 16 & 0.5 \\
\hline$(R)$-limonene & 0.125 & $<0.125$ & $<0.125$ & 8 & 4 & 8 & 0.25 \\
\hline
\end{tabular}

EMB—ethambutol; RMP—rifampicin; INH—isoniazid.

Table 4. The minimal inhibitory concentration values (MIC) obtained for terpenes tested in the presence of subinhibitory concentrations of antibiotics.

\begin{tabular}{|c|c|c|c|c|c|c|c|}
\hline & \multicolumn{7}{|c|}{ MIC $(\mu \mathrm{g} / \mathrm{mL})$ for $\alpha$-Pinene in the Presence of Antibiotics } \\
\hline & H37Ra & H37Rv & 192 & 12331 & $253 / 16$ & $85 / 13$ & 126 \\
\hline EMB & 8 & 128 & 128 & $>512$ & 256 & 512 & 128 \\
\hline RMP & 8 & 64 & 64 & $>512$ & 256 & 512 & 64 \\
\hline \multirow[t]{3}{*}{ INH } & 128 & 64 & 64 & $>512$ & 256 & 512 & 128 \\
\hline & \multicolumn{7}{|c|}{ MIC $(\mu \mathrm{g} / \mathrm{mL})$ for Sabinene in the Presence of Antibiotics } \\
\hline & H37Ra & H37Rv & 192 & 12331 & 253/16 & $85 / 13$ & 126 \\
\hline EMB & 4 & 128 & 128 & $>512$ & 256 & 512 & 128 \\
\hline RMP & 4 & 128 & 128 & $>512$ & 256 & 512 & 128 \\
\hline \multirow[t]{3}{*}{ INH } & 8 & 128 & 128 & $>512$ & 256 & 512 & 128 \\
\hline & \multicolumn{7}{|c|}{ MIC $(\mu \mathrm{g} / \mathrm{mL})$ for Bisabolol in the Presence of Antibiotics } \\
\hline & H37Ra & H37Rv & 192 & 12331 & $253 / 16$ & $85 / 13$ & 126 \\
\hline EMB & 2 & 16 & 16 & 256 & 128 & 128 & 32 \\
\hline RMP & 4 & 8 & 8 & 64 & 128 & 128 & 32 \\
\hline \multirow[t]{3}{*}{ INH } & 32 & 8 & 16 & 64 & 128 & 128 & 16 \\
\hline & \multicolumn{7}{|c|}{ MIC $(\mu \mathrm{g} / \mathrm{mL})$ for $\beta$-Elemene in the Presence of Antibiotics } \\
\hline & H37Ra & H37Rv & 192 & 12331 & $253 / 16$ & $85 / 13$ & 126 \\
\hline EMB & 2 & 128 & 128 & 256 & 256 & $>512$ & 256 \\
\hline RMP & 2 & 128 & 128 & 256 & 256 & 256 & 256 \\
\hline \multirow[t]{3}{*}{ INH } & 4 & 128 & 128 & 256 & 256 & $>512$ & 256 \\
\hline & \multicolumn{7}{|c|}{ MIC $(\mu \mathrm{g} / \mathrm{mL})$ for Myrcene in the Presence of Antibiotics } \\
\hline & H37Ra & H37Rv & 192 & 12331 & $253 / 16$ & $85 / 13$ & 126 \\
\hline EMB & 8 & 256 & 256 & 512 & $>512$ & $>512$ & 256 \\
\hline RMP & 2 & 256 & 256 & 512 & $>512$ & $>512$ & 256 \\
\hline INH & 64 & 256 & 256 & 512 & $>512$ & $>512$ & 256 \\
\hline
\end{tabular}


Table 4. Cont.

\begin{tabular}{|c|c|c|c|c|c|c|c|}
\hline & \multicolumn{7}{|c|}{ MIC $(\mu \mathrm{g} / \mathrm{mL})$ for $(S)$-Limonene in the Presence of Antibiotics } \\
\hline & H37Ra & H37Rv & 192 & 12331 & $253 / 16$ & $85 / 13$ & 126 \\
\hline EMB & 2 & 256 & 256 & 512 & $>512$ & $>512$ & 256 \\
\hline RMP & 0.5 & 256 & 256 & 512 & $>512$ & $>512$ & 256 \\
\hline \multirow[t]{3}{*}{$\mathrm{INH}$} & 32 & 256 & 256 & 512 & $>512$ & $>512$ & 256 \\
\hline & \multicolumn{7}{|c|}{ MIC $(\mu \mathrm{g} / \mathrm{mL})$ for $(R)$-Limonene in the Presence of Antibiotics } \\
\hline & H37Ra & H37Rv & 192 & 12331 & $253 / 16$ & $85 / 13$ & 126 \\
\hline EMB & 2 & 64 & 64 & 128 & 128 & 256 & 128 \\
\hline RMP & 0.5 & 64 & 64 & 64 & 256 & 256 & 256 \\
\hline INH & 32 & 64 & 64 & 128 & 128 & 256 & 128 \\
\hline
\end{tabular}

EMB—ethambutol; RMP—rifampicin; INH—isoniazid.

Table 5. The fractional inhibitory concentration indices obtained for combinations of terpenes and antibiotics.

\begin{tabular}{cccccccc}
\hline & \multicolumn{7}{c}{ FICI Values Obtained for Mycobacterial Strains } \\
\cline { 2 - 7 } & H37Ra & H37Rv & $\mathbf{1 9 2}$ & $\mathbf{1 2 3 3 1}$ & $\mathbf{2 5 6 / 1 6}$ & $\mathbf{8 5 / 1 3}$ & $\mathbf{1 2 6}$ \\
\hline INH/bisabolol & 2 & 1.5 & 2 & 0.75 & 1.5 & 1.5 & 1 \\
INH/myrcene & 1 & 2 & 2 & 2 & 2 & 2 & 2 \\
INH/ $(R)$-limonene & 2 & 1.5 & 1.5 & 1.5 & 1 & 1.5 & 1.5 \\
INH/(S)-limonene & 0.6 & 2 & 2 & 2 & 2 & 2 & 2 \\
INH/sabinene & 0.6 & 2 & 2 & 2 & 2 & 2 & 2 \\
INH/ $\alpha$-pinene & 2 & 1.5 & 1.5 & 2 & 2 & 2 & 2 \\
INH/ $\beta$-elemene & 0.6 & 1.5 & 1.5 & 2 & 1.5 & 2 & 2 \\
EMB/bisabolol & 1 & 1.5 & 2 & 1.5 & 1.5 & 2 & 1.5 \\
EMB/myrcene & 0.2 & 2 & 2 & 2 & 2 & 2 & 2 \\
EMB/(R)-limonene & 0.3 & 1 & 1.5 & 1.5 & 1 & 2 & 1.5 \\
EMB/(S)-limonene & 0.1 & 2 & 2 & 2 & 1.5 & 2 & 2 \\
EMB/sabinene & 0.2 & 2 & 2 & 2 & 2 & 2 & 2 \\
EMB/ $\alpha$-pinene & 0.3 & 1.5 & 2 & 2 & 1.5 & 2 & 2 \\
EMB/ $\beta$-elemene & 0.3 & 1.5 & 1.5 & 2 & 1.5 & 2 & 2 \\
RMP/bisabolol & 0.1 & 1 & 1.5 & 0.75 & 1.5 & 1.5 & 1.5 \\
RMP/myrcene & 0.1 & 2 & 2 & 2 & 2 & 2 & 2 \\
RMP/(R)-limonene & 0.1 & 1 & 1.5 & 1 & 1.5 & 1.5 & 2.5 \\
RMP/(S)-limonene & 0.1 & 2 & 2 & 2 & 2 & 2 & 2 \\
RMP/sabinene & 0.1 & 2 & 2 & 2 & 2 & 2 & 2 \\
RMP/ $\alpha$-pinene & 0.1 & 1.5 & 1.5 & 2 & 2 & 2 & 1.5 \\
RMP/ $\beta$-elemene & 0.1 & 1.5 & 1.5 & 2 & 1.5 & 1.5 & 2 \\
\hline
\end{tabular}

Synergism $\leq 0.5$; indifference $>0.5$ to $\leq 4$; antagonism $>4$ EMB—ethambutol; RMP—rifampicin; INH—isoniazid.

\subsection{Virulent, Sensitive and Drug-Resistant Strains}

Among tested terpenes, bisabolol showed the highest activity against all investigated strains, sensitive and resistant as well. The lowest MIC value obtained for this compound on H37Rv and 192 strains equaled to $16 \mu \mathrm{g} / \mathrm{mL}$. Likewise, INH-resistant strain 126, was quite susceptible to bisabolol, compared to the other terpenes (Table 2). The antimycobaterial activity of $(R)$-limonene followed bisabolol and was rather similar against all tested strains (MIC $=128-256 \mu \mathrm{g} / \mathrm{mL}$ ). The weakest activity was observed for other terpenes against multidrug resistant strains (MIC $\geq 512 \mu \mathrm{g} / \mathrm{mL}$ ) (Table 2). When antibiotics were tested in a presence of terpenes, bisabolol and $(R)$-limonene positively influenced the activity of antibiotics against majority of investigated strains. MIC values obtained for rifampicin was lowered at least two-fold in the presence of bisabolol and $(R)$-limonene for drug resistant isolates and reference strains. Similar pattern was observed for ethambutol, however the multidrug resistant 85/13 strain was not influenced. In case of isoniazid, bisabolol and $(R)$-limonene 
decreased MIC values two fold for all drug resistant isolates (Table 3-bolded values). It is also worth to notice that antimycobacterial activity of antibiotics against susceptible isolate 192 was not influenced by any of tested compounds. The evaluation of tuberculostatic activity of terpenes in the presence of subinhibitory concentrations of antibiotics resulted in MIC values obtained for sabinene, myrcene and (S)-limonene equal to these obtained for individual compounds for all virulent strains (Table 4). Only slightly increased antimycobacterial action was observed for almost all strains and drug combinations. The FICI indices obtained for combinations of tested compounds indicated an indifference in case of all virulent strains (FICI $>0.5$ but $\leq 4)$ (Table 5$)$.

\subsection{Cytotoxicity Evaluation}

The cytotoxicity evaluation revealed that limonenes and $\alpha$-pinene are non-toxic, as GMK cells (monkey kidney epithelial cells) maintained high viability (approx. 90\%) upon exposure to the highest tested concentration $(500 \mu \mathrm{g} / \mathrm{mL})$. Thus, determination of $\mathrm{IC}_{50}$ values for these compounds was impossible because it appears to be much higher than $500 \mu \mathrm{g} / \mathrm{mL}$ (the highest tested concentration). Lower $\mathrm{IC}_{50}$ value was obtained for sabinene $(348 \mu \mathrm{g} / \mathrm{mL})$, whereas $\alpha$-bisabolol showed slight cytotoxic effect against GMK cells $(71.12 \mu \mathrm{g} / \mathrm{mL}$ ) (Table 6$)$. However, $\mathrm{IC}_{50}$ value of sabinene was still higher than $\mathrm{IC}_{50}$ value of reference drug-rifampicin $(141.5 \mu \mathrm{g} / \mathrm{mL})$. According to da Silva et al., myrcene also did not present cytotoxic activity up to a concentration of $200 \mu \mathrm{g} / \mathrm{mL}$ against a Vero cell line (another monkey kidney epithelial cell line) [33]. $\beta$-Elemene is used as a broad spectrum antineoplastic agent and has been the subject of many clinical trials [34], hence it is regarded as safe.

Table 6. Cytoxicity of tested terpenes and antibiotics.

\begin{tabular}{cc}
\hline Tested Agent & IC $_{50}(\mu \mathrm{g} / \mathrm{mL})$ \\
\hline$\alpha$-Bisabolol & 71.12 \\
$(S)$-Limonene & $>500$ \\
$(R)$-Limonene & $>500$ \\
$\alpha$-Pinene & $>500$ \\
Sabinene & 348 \\
$\beta$-Elemene & $\mathrm{ND}$ \\
Myrcene & $200^{*}$ \\
Rifampicin & 141.5 \\
Isoniazid & $>500$ \\
\hline
\end{tabular}

* determined on Vero cell Line [31]; ND—not determined.

\section{Discussion}

A synergistic action of drug-drug combinations is defined as greater activity than the activity of the sum of the individual components [12]. This effect is desirable and leading to a better antimicrobial therapy efficacy. On account of emergence of multi- and extensively drug-resistant Mtb strains the combinations of drugs with natural compounds are tested to search for enhancers of antibiotics activity [35]. Also our study aimed to investigate the possible interactions between terpenes, constituents of essential oils, and antimycobacterial antibiotics against drug-resistant clinical isolates and reference Mtb strains. We also performed cytotoxicity evaluation of tested compounds against eukaryotic cells.

The in-vitro cytotoxicity determination for terpenes ( $\alpha$-bisabolol, $(S)$-limonene, $(R)$-limonene, $\alpha$-pinene and sabinene) and literature data (myrcene, $\beta$-elemene) $[33,34]$ showed that they are non-toxic against eukaryotic cells (green monkey kidney cells: Vero or GMK cell line).

The antimycobacterial activity of tested terpenes was described for a panel of Mtb strains (including clinical isolates) for a first time. However several of these compounds (sabinene, myrcene and limonene) were previously screened against reference virulent strain H37Rv. The MIC values obtained in our study for sabinene, myrcene and limonene were significantly higher than previously described by Andrade-Ochoa et al. [36] but this can be explained by different method applied for 
evaluation of inhibitory activity of tested compounds (visual evaluation, 21 day of incubation in our study and Alamar Blue technique, 8 days of incubation in the cited paper). Regardless the method used the activity of these three compounds was on the similar level. Among other terpenes, the interesting activity was shown by thymol and carvacrol $(0.78$ and $2.02 \mu \mathrm{g} / \mathrm{mL}$, respectively), while the highest MIC values were obtained for $p$-cymene and $\beta$-caryophyllene (91 and $100 \mu \mathrm{g} / \mathrm{mL}$, respectively) [36].

Taking into account the results of antimycobacterial activity of tested terpenes against different mycobacteria strains, it is difficult to correlate their activity with the structure, because the MIC values varied even by several orders for different strains, and the activity could not be described by any particular pattern. The quantitative structure-activity relationship studies performed by Andrade-Ochoa and coworkers revealed that the number of conjugated carbons, the number of phenolic and hydroxyl groups and the number of acceptor atoms of hydrogen bonds are the most important structural descriptors in the antimycobacterial activity of terpenes [36]. Compounds tested in this study were simple terpenes thus phenolic and hydroxyl groups nor oxygen atoms did not contribute to their antimycobacterial activity. The lowest MIC values observed for two-compounds combinations were descried for monocyclic sesquiterpene-bisabolol having a long side chain and for monocyclic monoterpene- $(R)$-limonene-with methyl and propylene groups. What is more interesting, there were significant differences in MIC values obtained for enantiomeric forms of limonene against mycobacterial strains (with exception of the avirulent strain H37Ra) and for combinations of limonenes with antiobiotics. $(R)$-Limonene occurs commonly in many plants but is especially abundant in citrus fruits, it has citrus odor, while the less often found (S)-limonene is a precursor in the biosynthesis of $(-)$-menthol and its odor is pine-like [37]. The distinction between these compounds is a different spatial arrangement of the propylene and methyl groups and it seems that more often naturally occurring isomer has also better antimicrobial properties, probably via specific interactions with mycobacterial cell envelope

The results from antimycobacterial assay showed that enhanced activity of ethambutol and rifampicin against H37Ra strain under the influence of studied terpenes may be correlated to the capability of essential oils constituents to modify the bacteria resistance mechanisms in general. Three possible scenarios can take place: inhibition of multidrug efflux pumps (farnesol in Mycobacterium smegmatis) [38], cell wall and membrane disturbance ( $\beta$-elemene and R-limonene in M. tuberculosis) [39] and alterations of quorum-sensing (Rose, geranium, lavender, clove essential oils in Escherichia coli) [40]. These may lead to better influx and retention of antibiotics inside the cells resulting their better efficacy. Our previous observations have shown that studied terpenes cause the changes in mycobacterium H37Ra cells shape, cell wall thickness and cytoplasm homogeneity in terms of uniformity and consistency [30]. Bacteria exposed to terpenes became filamentous (continuing to elongate but not to divide) what usually occurs under the oxidative stress, nutrient limitation or DNA damage and alters DNA replication and cell division [41]. Also other authors described similar morphological changes in pathogenic and spoilage-forming bacteria cells structures. The loose of regular cell shape and changes in cytoplasm and membrane integrity were observed under the influence of tea tree oil and some terpenes [40,42,43]. These findings suggest that cell wall and membrane disturbances caused by essential oils constituents may mainly contribute to the better penetration of antibiotics into the cells and their enhanced activity when tested in combinations.

However the important observations from this study are differences in avirulent and virulent bacteria susceptibility to terpenes tested individualy and in combinations with antibiotics. A comprehensive description of possible genetic variations, like multiple mutations, between virulent strain H37Rv and avirulent one, was described by Zheng and coworkers [44]. The changes found in H37Ra may account for its attenuation of virulence and various other phenotypic changes, like changes in bacteria susceptibility to antibiotics [44].Since synergistic interaction between antibiotics (ethambutol/rifmapicin) and terpenes was described only against avirulent strain H37Ra, the higher susceptibility of this strain to tested compounds may be related to the mutation in phoP gene, which is one of the factors leading to the inability of bacteria growth in human and murine macrophages [45-47]. 
The phoP gene encodes PhoP protein playing a key regulatory function in synthesis or transfer of metyl branched fatty acyl substituents found in polyketide-derived acyltrehaloses (sulfolipids SL, diacyltrehaloses DATs and polyacyltrehaloses PATs) [48,49]. The absence of these lipids in the cell wall was described in H37Ra mutant strain $[47,50]$ and this may contribute to the better action of terpenes themselves and in combination with antibiotics. The antibacterial activity of terpenes leading to the increased membrane permeability is dependent on the bacterial membrane net surface charge [9], which in physiological conditions is negative $[9,51-53]$. However during interaction of bacteria with essential oils constituents it becomes less negative [9]. In case of H37Ra mutant strain, the lack of sulfolipids in cell wall may be responsible for the enhanced antibacterial activity since sulfation gives an anionic form to a complex lipids of mycobacterial envelope and improves the lipid solubilization [54]. What is more, the experiments performed by Trombetta et al., suggest a real transfer of terpenes through cell membrane and possibility of their interaction with intracellular elements [11] but this action is strongly dependent on the lipid composition of the cell envelope $[9,11,55,56]$. Hence the observed lack of synergistic action of combinations of terpenes and antibiotics in case of all virulent strains might be a consequence of their richer composition of cell envelope [11], especially regarding the presence of midchain methyl-branched fatty acids (10-methylhexadecanoic(16:1me(10)), 10-methyloctadecanoic acid (18:1me(10)), and 10-methylnonadecanoic acid (19:1me(10)) which are associated with tolerance mechanisms to xenobiotics and with the maintenance of membrane fluidity under different stress conditions $[57,58]$.

The literature data show synergistic interactions among antibiotics: isoniazid, rifampicin, and ethambutol $(18.1 \%$ of combinations with FICI $=0.6)$ or ofloxacin, rifampicin, and ethambutol $(91.3 \%$ of combinations with FICI $=0.31-0.62$ ) against $M$. tuberculosis H37Rv [59] or between antibiotics and natural products: oleic acid (in combination with isoniazid, rifampicin and ethambutol, FICI in a range 0.09-0.36), 7-methyljuglone (in combination with isoniazid, FICI $=0.2$ and with rifampicin, $\mathrm{FICI}=0.5$ ), usnic acid (with rifampicin, $\mathrm{FICI}=0.25-0.38$ ) against $M$. tuberculosis $\mathrm{H} 37 \mathrm{Rv}$ strain and some Mtb drug-resistant clinical isolates [2,60,61], however little is known about their mechanism of action. Apart from positive results, the lack of synergy against different bacterial species was also documented. In the study performed by Rey-Jurado et al., the indifference (FICI $=1.5-3$ ) was observed for all three-drug combinations of second-choice antituberculous antibiotics tested against multidrug-resistant $\mathrm{Mtb}$ isolates, showing all these combinations to be equally effective [62]. Also the combination of carvacrol, eugenol and cinnamaldehyde encapsulated within lipid nanocapsules and doxycycline tested against Acinetobacter baumannii SAN, A. baumannii $\mathrm{RCH}$, Klebsiella pneumoniae, Escherichia coli and Pseudomonas aeruginosa resulted in indifference (FICI $=0.7-1.30$ ) [63]. Nevertheless, despite the lack of synergy in these species, the scanning electron microscopy images showed holes in bacterial envelope and leakage of cellular contents after exposure to tested combination [63] indicating their influence on the bacterial cell wall/membrane which probably can be attributed to the action of essential oil constituents. What is more, we also observed that MIC values obtained for rifampicin was lowered at least two-fold in the presence of bisabolol and (R)-limonene for drug resistant isolates and reference strains although the synergy in action wasn't observed for these strains. This observation may suggest that disturbances in a cell envelope integrity may facilitate the intake of antibiotic also in virulent strains, however the extent of changes was too low to produce synergy. The other interesting observation from our study and from literature data $[60,61]$ showed that rifampicin produce positive interactions with natural compounds more often than INH, EMB or SM. This may be correlated with different target points of rifampicin (lipophilic compound inhibiting DNA-dependent RNA polymerase) [64] and terpenes (influencing cell wall and membrane), however it was not explained yet. Additional studies are needed for better understanding of interactions taking place in bacteria when antibiotics are combined with essential oils or its constituents. 


\section{Materials and Methods}

\subsection{Tested Compounds}

The first line antibiotics: rifampicin, isoniazid and ethambutol as well as natural terpenes: $\alpha$-pinene 98\%; (R)-limonene 97\%; (S)-limonene 98\%; myrcene 90\%, bisabolol 93\% were purchased from Sigma-Aldrich (St. Louis, MO, USA). Sabinene 99\% and $\beta$-elemene 97\% were isolated. Separation of sabinene and $\beta$-elemene was performed on Spectrum high-performance counter-current chromatographic equipment (Dynamic Extraction Co., Ltd., Slough, Berkshire, UK). Sabinene was obtained from commercially available Daucus carota seeds essential oil, as described previously [29], while $\beta$-elemene was isolated from Nigella damascena seed essential oil [65]. Briefly, mixture of $n$-hexane, acetonitrile and tert-butyl-methyl ether in a ratio 2:1:0.1 $(v / v)$ was used as two phase solvent system for sabinene purification, while $\beta$-elemene was separated with a mixture of petroleum ether, acetonitrile and acetone in a ratio of 2:1.5:0.5 $(v / v)$. Both separations were performed in reversed phase mode with a mobile phase flow rate equal to $6 \mathrm{~mL} / \mathrm{min}$ and the eluate was monitored at $210 \mathrm{~nm}$. The obtained one-minute fractions, collected from the beginning of the run, were checked for content and purity by means of gas chromatography-mass spectrometry [29]. 200 and $280 \mathrm{mg}$ of essential oil was used for semipreparative separation of $\beta$-elemene and sabinene, respectively.

\subsection{Mycobacterial Strains}

Two reference strains (avirulent Mtb H37Ra ATTC 25177 and virulent H37R $\mathrm{V}$ ATTC 25618) as well as five clinical isolates (192-strain susceptible; 12331—strain resistant to isoniazid (INH), rifampicin (RMP) and ethambutol (EMB); 256/16 —strain resistant to RMP; 85/13—strain belonging to a Beijing family, resistant to streptomycin, INH, RMP and EMB; 126-strain resistant to INH) were investigated. Clinical isolates were collected in National Tuberculosis and Lung Diseases Research Institute (Warsaw, Poland). Drug susceptibility of isolates to first-line antibiotics (EMB, streptomycin-SM, INH and RMP) was verified using a conventional indirect proportion method on Löwenstein-Jensen (L-J) medium [66].

\subsection{Spoligotyping}

All isolates were analyzed by spoligotyping as described previously [67]. In brief, amplified biotinylated PCR products were hybridized to a set of 43 oligonucleotides covalently bound to a membrane (Isogen Life Science B.V., Utrecht, The Netherlands). The resulting hybridization signals were revealed by enhanced chemiluminescence detection system (Amersham, Little Chalfont, UK) and were visualized by exposure to X-ray film (Hyperfilm ECL; Amersham) according to the manufacturer's instructions. The profiles were obtained by photochemical development of X-ray film. The resulting spoligotypes were converted from binary format to an octal code for comparison with the SITVIT2 proprietary database of the Pasteur Institute of Guadeloupe database (available online at http:/ / www.pasteur-guadeloupe.fr:8081/SITVITDemo). Major phylogenetic clades were assigned according to signatures provided in SpolDB4 [68].

\subsection{Minimal Inhibitory Concentration Determination}

Mtb strains were grown in Lowenstein-Jensen medium slants [69]. Colonies were suspended with sterile distilled water containing $5 \mathrm{~mm}$ glass beads and vortexed during $45 \mathrm{~s}$. The supernatant was harvested and adjusted to $0.5 \mathrm{McF}$ arland with a nephelometer (Becton, Dickinson \& Company, Franklin Lakes, MD, USA). For minimal inhibitory concentration (MIC) testing the inoculum was transferred to Difco ${ }^{\mathrm{TM}}$ Middlebrook $7 \mathrm{H} 9$ broth (Becton, Dickinson \& Company, Franklin Lakes, MD, USA) supplemented sodium chloride, bovine albumin fraction $\mathrm{V}$, dextrose and catalase (ADC enrichment, Becton, Dickinson \& Company, Franklin Lakes, MD, USA) and incubated in a presence of tested substances or their combinations at $37^{\circ} \mathrm{C}$ for 21 days. Afterwards, the lowest concentration at which no visible growth occurred was recorded to be the MIC value of the individual and combined antibacterial agents. The stock solutions of terpenes and antibiotics were prepared in dimethyl 
sulfoxide (DMSO). The individual MIC values for tested substances and antibiotics were determined in a range $0.125-512 \mu \mathrm{g} / \mathrm{mL}$. The concentration of terpenes tested in a presence of sub-inhibitory concentration of antibiotics was in a range $0.5-512 \mu \mathrm{g} / \mathrm{mL}$, whereas the range of concentration of antibiotics tested in a presence of sub-inhibitory concentration of terpenes was $0.0625-512 \mu \mathrm{g} / \mathrm{mL}$ for $\mathrm{Mtb}$ H37Ra and $0.125-512 \mu \mathrm{g} / \mathrm{mL}$ for other strains. The negative and positive control were consisted of medium without inoculum and medium inoculated with the same amount of bacteria as test vials kept in the same conditions as test vials, respectively. The highest concentration of DMSO used in the samples $(0.5 \%)$ was tested to evaluate any possible bactericidal effect of the solvent. All experiments were performed according to the CLSI standards [70] and in triplicate.

\subsection{Evaluation of Interactions between Terpenes and Antibiotics}

The Fractional Inhibitory Concentration Index (FICI) was calculated as follows: FICI = FICA + $\mathrm{FICB}=\mathrm{A} / \mathrm{MICA}+\mathrm{B} / \mathrm{MICB}$ where $\mathrm{A}$ and $\mathrm{B}$ were the MIC of each tested compound in combination and MICA and MICB were the MIC of each tested compound individually. The obtained FICI values were then used to determine whether synergism (FICI $\leq 0.5)$, indifference $(>0.5 \mathrm{FICI} \leq 4)$, or antagonism $(\mathrm{FICI}>4)$ occurred between the tested agents [71].

\subsection{Cytotoxicity Study}

The cytotoxicity experiment was performed using African green monkey kidney epithelial cells (GMK) obtained from BIOMED-Lublin S.A. (Lublin, Poland). The cells were cultured in EMEM medium (ATCC-LGC Standards, Cumberland, ME, USA) supplemented with $10 \%$ foetal bovine serum (FBS, Pan-Biotech, Aidenbach, Germany), penicillin $(100 \mathrm{U} / \mathrm{mL})$, and streptomycin $(100 \mu \mathrm{g} / \mathrm{mL})$ (Sigma-Aldrich, St. Louis, MO, USA). The GMK cells were maintained at $37^{\circ} \mathrm{C}$ in a humidified atmosphere of $5 \% \mathrm{CO}_{2}$ and $95 \%$ air. The GMK cells were seeded in 96-multiwell plates in $100 \mu \mathrm{L}$ of the complete EMEM medium at a concentration of $3 \times 10^{5}$ cells $/ \mathrm{mL}\left(3 \times 10^{4}\right.$ cells $/$ well $)$ and the plates were maintained at $37^{\circ} \mathrm{C}$ for $24 \mathrm{~h}$. Then, the culture medium was replaced with $100 \mu \mathrm{L}$ of different concentrations of tested agents and 2 reference anti-mycobacterial drugs-rifampicin and isoniazid. The stock solutions of all compounds were prepared in DMSO (Sigma-Aldrich, St. Louis, $\mathrm{MO}$, USA), thus the highest solvent concentrations ( $1 \%$ and $0.5 \%$ DMSO) used in the experiment were tested in parallel to exclude potential toxicity associated with the use of DMSO. Different concentrations of the tested agents were obtained by six serial 2-fold dilutions using culture medium (the highest tested concentration was equal $500 \mu \mathrm{g} / \mathrm{mL}$ ). GMK cells maintained in culture medium without anti-mycobacterial agent served as a negative control of cytotoxicity. The cells were exposed to tested compounds and reference drugs for $48 \mathrm{~h}$, then cytotoxicity test was performed using MTT assay (Sigma-Aldrich, St. Louis, MO, USA) as it was described previously [72]. The cytotoxicity test was repeated in three separate experiments $(n=3)$ and each experiment was carried out in quadruplicate. The $\mathrm{IC}_{50}$ values (concentration reducing viability of GMK cells by 50\%) were determined using GraphPad Prism 5, Version 5.03 software (GraphPad Software, Inc., La Jolla, CA, USA).

\section{Conclusions}

The performed study has shown positive synergistic results for combinations of natural terpenes and antimycobacterial antibiotics (INH, RMP) against avirulent H37Ra strain. The other observation were differences between avirulent and virulent bacterial susceptibility to terpenes tested alone and in combinations with antibiotics, which can be correlated with the differences in the cell wall structure between H37Ra mutant and all virulent strains. The presence of mid-chain methyl-branched fatty acids in the mycobacterial cell envelope resulted in better tolerance mechanisms to tested terpenes in virulent strains, however bisabolol and $(R)$-limonene also lowered the MIC values obtained for antibiotics in these less sensitive bacteria. 
Acknowledgments: This work was financially supported by grant No. 2013/11/D/NZ7/01613 from the Polish National Science Centre, as well as Ministry of Science and Higher Education in Poland within the DS2 project of the Medical University of Lublin. This work was developed using the equipment purchased within the agreement No. POPW.01.03.00-06-010/09-00 Operational Program Development of Eastern Poland 2007-2013, Priority Axis I, Modern Economy, Operations 1.3. Innovations Promotion.

Author Contributions: E.S., R.S. and E.A.-K. conceived and designed the experiments; M.S.-O., A.N. and A.P. performed the experiments; E.S. and G.G. analyzed the data; E.S. wrote the paper.

Conflicts of Interest: The authors declare no conflict of interest.

\section{References}

1. World Health Organization (WHO). Global Tuberculosis Report; World Health Organization: Rome, Italy, 2016; pp. 1-3.

2. Ge, F.; Zeng, F.; Liu, S.; Guo, N.; Ye, H.; Song, Y.; Fan, J.; Wu, X.; Wang, X.; Deng, X.; et al. In vitro synergistic interactions of oleanolic acid in combination with isoniazid, rifampicin or ethambutol against Mycobacterium tuberculosis. J. Med. Microbiol. 2010, 59, 567-572. [CrossRef] [PubMed]

3. Knezevic, P.; Aleksic, V.; Simin, N.; Svircev, E.; Petrovic, A.; Mimica-DUKic, N. Antimicrobial activity of Eucalyptus camaldulensis essential oils and their interactions with conventional antimicrobial agents against multi-drug resistant Acinetobacter baumannii. J. Ethnopharmacol. 2016, 178, 125-136. [CrossRef] [PubMed]

4. Rosato, A.; Vitali, C.; DeLaurentis, N.; Armenise, D.; Milillo, A.M. Antibacterial effect of some essential oils administered alone or in combination with norfloxacin. Phytomedecine 2007, 14, 727-732. [CrossRef] [PubMed]

5. Chen, Y.; Huang, S.; Sun, F.; Chiang, Y.; Chiang, C.; Tsai, C.; Wenga, C. Transformation of cinnamic acid from trans- to cis-form raises a notable bactericidal and synergistic activity against multiple-drug resistant Mycobacterium tuberculosis. Eur. J. Pharm. Sci. 2011, 43, 188-194. [CrossRef] [PubMed]

6. Rastogi, N.; Goh, K.S.; Horgen, L.; Barrow, W.W. Synergistic activities of antituberculous drugs with cerulenin and trans-cinnami cacid against Mycobacterium tuberculosis. FEMS Immunol. Med. Microbiol. 1998, 21, 149-157. [CrossRef] [PubMed]

7. Silva, F.; Ferreira, S.; Duarte, A.; Mendonça, D.I.; Domingues, F.C. Antifungal activity of Coriandrum sativum essential oil, its mode of action against Candida species and potential synergism with amphotericin B. Phytomedicine 2011, 19, 42-47. [CrossRef] [PubMed]

8. Cristani, M.D.; Arrigo, M.; Mandalari, G.; Castelli, F.; Sarpietro, M.G.; Micieli, D.; Venuti, V.; Bisignano, G.; Saija, A.; Trombetta, D. Interaction of four monoterpenes contained in essential oils with model membranes: Implications for their antibacterial activity. J. Agric. Food Chem. 2007, 55, 6300-6308. [CrossRef] [PubMed]

9. Lopez-Romero, J.C.; González-Ríos, H.; Borges, A.; Simões, M. Antibacterial effects and mode of action of selected essential oils components against Escherichia coli and Staphylococcus aureus. Evid. Based Complement. Altern. Med. 2015, 2015, 795435. [CrossRef] [PubMed]

10. Nazzaro, F.; Fratianni, F.; De Martino, L.; Coppola, R.; De Feo, V. Effect of essential oils on pathogenic bacteria. Pharmaceuticals 2013, 6, 1451-1474. [CrossRef] [PubMed]

11. Trombetta, D.; Castelli, F.; Sarpietro, M.G.; Venuti, V.; Cristani, M.; Daniele, C.; Saija, A.; Mazzanti, G.; Bisignano, G. Mechanisms of antibacterial action of three monoterpenes. Antimicrob. Agents Chemother. 2005, 49, 2474-2478. [CrossRef] [PubMed]

12. Hyldgaard, M.; Mygind, T.; Meyer, R.L. Essential oils in food preservation: Mode of action, synergies, and interactions with food matrix components. Front. Microbiol. 2012, 25, 3-12. [CrossRef] [PubMed]

13. Langeveld, W.T.; Veldhuizen, E.J.A.; Bur, S.A. Synergy between essential oil components and antibiotics: A review. Crit. Rev. Microbiol. 2014, 40, 76-94. [CrossRef] [PubMed]

14. Rosato, A.; Piarulli, M.; Corbo, F.; Muraglia, M.; Carone, A.; Vitali, M.E.; Vitali, C. In vitro synergistic antibacterial action of certain combinations of gentamicin and essential oils. Curr. Med. Chem. 2010, 17, 3289-3295. [CrossRef] [PubMed]

15. Moussaoui, F.; Alaoui, T. Evaluation of antibacterial activity and synergistic effect between antibiotic and the essential oils of some medicinal plants. Asian Pac. J. Trop. Biomed. 2016, 6, 32-37. [CrossRef]

16. Dudek, G.; Grzywna, Z.J.; Willco, M.L. Classification of antituberculosis herbs for remedial purposes by using fuzzy sets. BioSystems 2008, 94, 285-289. [CrossRef] [PubMed] 
17. Baser, K.H.C.; Buchbauer, G. Handbook of Essential Oils: Science, Technology, and Applications; CRC Press: Boca Raton, FL, USA, 2015.

18. Sjodin, K.; Persson, M.; Faldt, J.; Ekberg, I.; Borg-Karlson, A.K. Occurrence and correlations of monoterpene hydrocarbon enantiomers in pinus sylvestris and picea abies. J. Chem. Ecol. 2000, 26, 1701-1720. [CrossRef]

19. Zheljazkov, V.D.; Semerdjieva, I.B.; Dincheva, I.; Kacaniova, M.; Astatkie, T.; RadoUKova, T.; Schlegel, V. Antimicrobial and antioxidant activity of Juniper galbuli essential oil constituents eluted at different times. Ind. Crops Prod. 2017, 109, 529-537. [CrossRef]

20. Zebib, B.; Beyrouthy, M.E.L.; Sarfi, C.; Merah, O. Chemical composition of the essential oil of Ssatureja myrtifolia (Boiss. \& Hohen.) from Lebanon. J. Essent. Oil-Bear. Plants 2015, 18, 248-254.

21. Healthcare, T. PDR for Herbal Medicine; Medical Economics Company: Montvale, NJ, USA, 2007.

22. Padovan, A.; Keszei, A.; Kulheim, C.; Foley, W.J. The evolution of foliar terpene diversity in myrtaceae. Phytochem. Rev. 2014, 13, 695-716.

23. Fall, R.; Ngom, S.; Sall, D.; Sembene, M.; Samb, A. Chemical characterization of essential oil from the leaves of Callistemon viminalis (D.R.) and Melaleuca leucadendron (Linn.). Asian Pac. J. Trop. Biomed. 2017, 4, 347-351. [CrossRef]

24. Kamatou, G.P.P.; Viljoen, A.M.A. Review of the application and pharmacological properties of alpha-bisabolol and alpha-bisabolol-rich oils. J. Am. Oil Chem. Soc. (JAOCS) 2010, 87, 1-7. [CrossRef]

25. Wang, S.; Zhao, Z.; Sun, Y.-T.; Zeng, Z.; Zhan, X.; Li, C.; Xie, T. A review of medicinal plant species with elemene in China. Afr. J. Pharm. Pharmacol. 2012, 6, 3032-3040. [CrossRef]

26. Borek, T.T.; Hochrein, J.M.; Irwin, A.N. Composition of the Essential Oils from Rocky Mountain Juniper (Juniperus scopulorum), Big Sagebrush (Artemisia tridentata), and White Sage (Salvia Apiana); Sandia National Laboratories: Albuquerque, NM, USA, 2003.

27. Maya, K.M.; Zachariach, T.J.; Krishnamoorthy, B. Chemical composition of essential oil of nutmeg (Mmyristica fragrans Hout) accessions. J. Species Aromat. Crops 2004, 13, 135-139.

28. Rouatbi, M.; Duquenoy, A.; Giampaoli, P. Extraction of the essential oil of thyme and black pepper by superheated steam. J. Food Eng. 2007, 78, 708-714. [CrossRef]

29. Sieniawska, E.; Swiatek, L.; Rajtar, B.; Kozioł, E.; Polz-Dacewicz, M.; Skalicka-Wozniak, K. Carrot seed essential oil-Source of carotol and cytotoxicity study. Ind. Crops Prod. 2016, 92, 109-115. [CrossRef]

30. Sieniawska, E.; Swatko-Ossor, M.; Sawicki, R.; Ginalska, G. Morphological changes in the overall Mycobacterium tuberculosis H37Ra cell shape and cytoplasm homogeneity due to Mutellina purpurea L. Essential oil and its main constituents. Med. Princ. Pract. 2015, 24, 527-532. [CrossRef] [PubMed]

31. Sieniawska, E.; Swatko-Osso, M.; Sawicki, R.; Skalicka-Woźniak, K.; Ginalska, G. Natural terpenes influence the activity of antibiotics against isolated Mycobacterium tuberculosis. Med. Princ. Pract. 2017, 26, 1-17. [CrossRef] [PubMed]

32. Warren, R.M.; Streicher, E.M.; Charalambous, S.; Churchyard, G.; Van der Spuy, G.D.; Grant, A.D.; Van Helden, P.D.; Victor, C.T. Use of spoligotyping for accurate classification of recurrent tuberculosis. J. Clin. Microbiol. 2002, 40, 3851-3853. [CrossRef] [PubMed]

33. Da Silva, S.L.; Figueiredo, P.M.; Yano, T. Cytotoxic evaluation of essential oil from Zanthoxylum rhoifolium Lam. Leaves. Acta Amazon. 2007, 37, 281-286. [CrossRef]

34. Huang, L. Synthesis of (-)-Beta-elemene, (-)-Beta-elemenal, (-)-Beta-elemenol, (-)-Beta-elemene Fluoride and Their Analogues, Intermediates and Composition and Uses Thereof. WO 2006016912 A2, 16 February 2006.

35. Nguta, J.M.; Appiah-Opong, R.; Nyarko, A.K.; Yeboah-Manu, D.C.; Addo, P.G.A. Current perspectives in drug discovery against tuberculosis from natural products. Int. J. Mycobacteriol. 2015, 4, 165-183. [CrossRef] [PubMed]

36. Andrade-Ochoa, S.; Nevárez-Moorillón, G.V.; Sánchez-Torres, L.E.; Villanueva-García, M.; Sánchez-Ramírez, B.E.; Rodríguez-Valdez, L.M.; Rivera-Chavira, B.E. Quantitative structure-activity relationship of molecules constituent of different essential oils with antimycobacterial activity against Mycobacterium tuberculosis and Mycobacterium bovis. BMC Complement. Altern. Med. 2015, 15, 333. [CrossRef] [PubMed]

37. Bouwmeester, H.J.; Gershenzon, J.; Konings, M.C.J.M.; Croteau, R. Biosynthesis of the monoterpenes limonene and carvone in the fruit of caraway. I. Demonstration of enzyme activities and their changes with development. Plant Physiol. 1998, 117, 901-912. [CrossRef] [PubMed] 
38. Jin, J.; Zhang, J.Y.; Guo, N.; Sheng, H.; Li, L.; Liang, J.C.; Wang, X.L.; Li, Y.; Liu, M.Y.; Wu, X.P.; et al. Farnesol, a potential efflux pump inhibitor in Mycobacterium smegmatis. Molecules 2010, 15, 7750-7762. [CrossRef] [PubMed]

39. Sawicki, R.; Sieniawska, E.; Swatko-Ossor, M.; Golus, J.; Ginalska, G. The frequently occurring components of essential oils beta-elemene and $R$-limonene alter expression of dprE1 and clgr genes of mycobacterium tuberculosis h37ra. Food Chem. Toxicol. 2017, 145-149. [CrossRef] [PubMed]

40. Yap, P.S.X.; Yiap, B.C.; Ping, H.C.; Lim, S.H.E. Essential oils, a new horizon in combating bacterial antibiotic resistance. Open Microbiol. J. 2014, 8, 6-14. [CrossRef] [PubMed]

41. Young, K.D. The selective value of bacterial shape. Microbiol. Mol. Biol. Rev. 2006, 70, 660-703. [CrossRef] [PubMed]

42. Carson, C.F.; Mee, B.J.; Riley, T.V. Mechanism of action of Melaleuca alternifolia (tea tree) oil on Staphylococcus aureus determined by time-kill, lysis, leakage, and salt tolerance assays and electron microscopy. Antimicrob. Agents Chemother. 2002, 46, 1914-1920. [CrossRef] [PubMed]

43. Reichling, J.; Harkenthal, M.; Geiss, H.; Hoppe-Tichy, T.; Saller, R. Electron microscopic and biochemical investigations on the antibacterial effects of Australian tea tree oil against Staphylococcus aureus. Curr. Top. Phytochem. 2002, 5, 77-84.

44. Zengin, H.; Baysal, A.H. Antibacterial and antioxidant activity of essential oil terpenes against pathogenic and spoilage-forming bacteria and cell structure-activity relationships evaluated by sem microscopy. Molecules 2014, 19, 17773-17798. [CrossRef] [PubMed]

45. Lee, J.S.; Krause, R.; Schreiber, J.; Krause, R.; Schreiber, J.; Mollenkopf, H.J.; Kowall, J.; Stein, R.; Jeon, B.Y.; Kwak, J.Y.; et al. Mutation in the transcriptional regulator phop contributes to avirulence of Mycobacterium tuberculosis H37Ra strain. Cell Host Microbe 2008, 3, 97-103. [CrossRef] [PubMed]

46. Perez, E.; Samper, S.; Bordas, Y.; Guilhot, C.; Gicquel, B.; Martin, C. An essential role for phop in Mycobacterium tuberculosis virulence. Mol. Microbiol. 2001, 41, 179-187. [CrossRef] [PubMed]

47. Walters, S.B.; Dubnau, E.; Kolesnikova, I.; Laval, F.; Daffe, M.; Smith, I. The Mycobacterium tuberculosis phopr two-component system regulates genes essential for virulence and complex lipid biosynthesis. Mol. Microbiol. 2006, 60, 312-330. [CrossRef] [PubMed]

48. Das, A.K.; Kumar, V.A.; Sevalkar, R.R.; Bansal, R.; Sarkar, D. Unique n-terminal arm of Mycobacterium tuberculosis phop protein plays an unusual role in its regulatory function. J. Biol. Chem. 2013, 288, 29182-29192. [CrossRef] [PubMed]

49. Goyal, R.; Das, A.K.; Singh, R.; Singh, P.K.; Korpole, S.; Sarkar, D. Phosphorylation of Phop protein plays direct regulatory role in lipid biosynthesis of Mycobacterium tuberculosis. J. Biol. Chem. 2011, 286, 45197-45208. [CrossRef] [PubMed]

50. Asensio, J.G.; Maia, C.; Ferrer, N.L.; Walters, S.B.; Laval, F.; Barilone, N.; Laval, F.; Soto, C.Y.; Winter, N.; Daffe, M.; et al. The virulence-associated two component phop-phor system controls the biosynthesis of polyketide-derived lipids in Mycobacterium tuberculosis. J. Biol. Chem. 2006, 281, 1313-1316. [CrossRef] [PubMed]

51. Gilbert, P.; Evans, D.J.; Evans, E.; Duguid, I.G.; Brown, M.R.W. Surface characteristics and adhesion of Escherichia coli and Staphylococcus epidermidis. J. Appl. Bacteriol. 1991, 71, 72-77. [PubMed]

52. Lerebour, G.; Cupferman, S.; Bellon-Fontaine, M.N. Adhesion of Staphylococcus aureus and Staphylococcus epidermidis to the episkin reconstructed epidermis model and to an inert stainless steel substrate. J. Appl. Microbiol. 2004, 97, 7-16. [CrossRef] [PubMed]

53. Palmer, J.; Flint, S.; Brooks, J. Bacterial cell attachment, the beginning of a biofilm. J. Ind. Microbiol. Biotechnol. 2007, 34, 577-588. [CrossRef] [PubMed]

54. Rhoades, E.R.; Streeter, C.; Turk, J.; Hsu, F.F. Characterization of sulfolipids of Mycobacterium tuberculosis H37Rv by multiple-stage linear ion-trap high-resolution mass spectrometry with electrospray ionization reveals that the family of sulfolipid II predominates. Biochemistry 2011, 50, 9135-9147. [CrossRef] [PubMed]

55. Helander, I.M.; Alakomi, H.L.; Latva-Kala, K.; Mattila-Sandholm, T.; Pol, I.; Smid, E.J.; Gorris, L.G.M.; von Wright, A. Characterization of the action of selected essential oil components on gram-negative bacteria. J. Agric. Food Chem. 1998, 46, 3590-3595. [CrossRef]

56. Shrivastava, S.; Bera, T.; Roy, A.; Singh, G.; Ramachandrarao, P.; Dash, D. Characterization of enhanced antibacterial effects of novel silver nanoparticles. Nanotechnology 2007, 18, 225103. [CrossRef] 
57. Frostegard, A.; Tunlid, A.; Baath, E. Phospholipid fatty acid comcosition, biomass, and activity of microbial communities from two soil types experimentally exposed to different heavy metals. Appl. Environ. Microbiol. 1993, 199, 3605-3617.

58. Poger, D.; Caron, B.; Mark, A.E. Effect of methyl-branched fatty acids on the structure of lipid bilayers. J. Phys. Chem. B 2014, 118, 13838-13848. [CrossRef] [PubMed]

59. Rey-Jurado, E.; Tudó, G.; Martínez, J.A.; González-Martín, J. Synergistic effect of two combinations of antituberculous drugs against Mycobacterium tuberculosis. Tuberculosis 2012, 92, 260-263. [CrossRef] [PubMed]

60. Bapela, N.B.; Lall, N.; Fourie, F.B.; Franzblau, S.G.; Van Rensburg, C.E.J. Activity of 7-methyl-juglone in combination with antituberculous drugs against Mycobacterium tuberculosis. Phytomedicine 2006, 13, 630-635. [CrossRef] [PubMed]

61. Ferraz-Carvalho, R.S.; Pereira, M.A.; Linhares, L.A.; Lira-Nogueira, M.C.B. Effects of the encapsulation of usnic acid into liposomes and interactions with antituberculous agents against multidrug-resistant tuberculosis clinical isolates. Memórias do Instituto Oswaldo Cruz 2016, 111, 330-334. [CrossRef] [PubMed]

62. Rey-Jurado, E.; Tudó, G.; De la Bellacasa, J.P.; Espasa, M.; González-Martín, J. In vitro effect of three-drug combinations of antituberculous agents against multidrug-resistant Mycobacterium tuberculosis isolates. Int. J. Antimicrob. Agents 2013, 41, 278-280. [CrossRef] [PubMed]

63. Valcourt, C.; Saulnier, P.; Umerska, A.; Zanelli, M.P.; Montagu, A.; Rossines, E.; Joly-Guillou, M.L. Synergistic interactions between doxycycline and terpenic components of essential oils encapsulated within lipid nanocapsules against gram negative bacteria. Int. J. Pharm. 2016, 498, 23-31. [CrossRef] [PubMed]

64. Campbell, E.A.; Korzheva, N.; Mustaev, A.; Murakami, K.; Nair, S.; Goldfarb, A.; Darst, S.A. Structural mechanism for rifampicin inhibition of bacterial RNA polymerase. Cell 2001, 104, 901-912. [CrossRef]

65. Sieniawska, E.; Sawicki, R.; Swatko-Ossor, M.; Ginalska, G.; Skalicka-Wozniak, K. Nigella damascena L. Essential oil-A source of $\beta$-elemene for antimycobacterial testing. In Proceedings of the 48th International Symposium on Essential Oils (ISEO2017), Pécs, Hungary, 10-13 September 2017; p. 53.

66. Augustynowicz-Kopec, E.; Zwolska, Z. Tuberculosis caused by xdr resistant Mycobacterium tuberculosis in Poland. Microbiological and molecular analysis. Pol. Pulmonol. Allergol. 2007, 75, 32-39.

67. Augustynowicz-Kopec, E.; Zwolska, Z. Progress in diagnostics and the molecular epidemiology of Mycobacterium tuberculosis. Adv. Microbiol. 2010, 49, 151-156.

68. Brudey, K.; Driscoll, J.R.; Rigouts, L.; Prodinger, W.M.; Gori, A.; Al-Hajoj, S.A.; Allix, C.; Aristimuño, L.; Arora, J.; Baumanis, V.; et al. Mycobacterium tuberculosis complex genetic diversity: Mining the fourth international spoligotyping database (SpolDB4) for classification, population genetics and epidemiology. BMC Microbiol. 2006, 6, 23-24. [CrossRef] [PubMed]

69. Zwolska, Z.; Augustynowicz-Kopec, E.; Klatt, M. Primary and bcquired drug resistance of tuberculosis bacilli in Poland. Pol. Pulmonol. Allergol. 1999, 67, 536-545.

70. Clinical and Laboratory Standards Institute (CLSI). Methods for Determining Bactericidal Activity of Antimicrobial Agents. Approved Guideline; CLSI Document M26-A; Clinical and Laboratory Standards Institute: Wayne, PA, USA, 1999.

71. Odds, F.C. Synergy, antagonism, and what the chequerboard puts between them. J. Antimicrob. Chemother. 2003, 52, 1-2. [CrossRef] [PubMed]

72. Kolmas, J.; Pajor, K.; Pajchel, L.; Przekora, A.; Ginalska, G.; Oledzka, E.; Sobczak, M. Fabrication and physicochemical characterization of porous composite microgranules with selenium oxyanions and risedronate sodium for potential applications in bone tumors. Int. J. Nanomed. 2017, 12, 5633-5642. [CrossRef] [PubMed]

Sample Availability: Samples of the compounds are not available from the authors. 